\title{
The work of the cutting beater in the transition zone threshing and separating devices combine harvesters
}

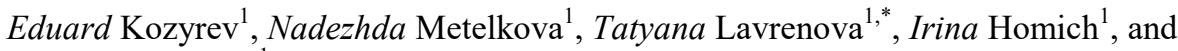 \\ Lyubov Filonenko ${ }^{1}$ \\ ${ }^{1}$ Don State Technical University, 1, Gagarin square, 344003, Rostov-on-Don, Russia
}

\begin{abstract}
In this article we studied the work of cutting beater in the transition zone of a combine harvester threshing drum. The influence of the parameters of the beater on the reflection of grains in its interaction with the heap flow and feed to the first stage of the straw-cutter is considered. A constructive scheme of the location of the working bodies of the transition zone showed a decrease in losses for straw.
\end{abstract}

\section{Introduction}

Modeling of the transition zone processes of the threshing and separating device of the combine harvester was performed by V.I. Zubkov [1]. This work complements his research by studying the influence of the beater design on the scattering of reflected grains and the subsequent separation process.

The task of studying the transition zone is select and justify the parameters and operating modes of the cutting beater, determine its position relative to the threshing apparatus and the surface of the front cascade of the straw walker in order to ensure the most complete separation in this zone and, ultimately, reduce losses behind the straw walker [3].

To organize the process in the transition zone, limited number of parameters are available for regulation. For the thresher, it is position of the outlet gap, i.e., the direction of the ejected stream. For a straw walker, structural parameters of the front cascade are available for regulation - the angle of inclination of the surface to the horizon line, its length and the distance from the beater to its surface [4]. The tilt angle is limited to a limit of 33 degrees. The distance from the axis of rotation of the beater to the surface of the cascade is determined by the height of the layer forming on the surface of the straw walker. The direction and speed of the stream transformed by the cutting beater are regulated by its design parameters and kinematic modes.

The limitation of the diameter of the cutting beater to the smaller side is determined by the depth of immersion of the blade in the zone of the initial flow and from the conditions of the optimal direction of the velocity vector of the converted stream [5]. The diameter of the beater in a large direction has no restrictions and is determined from design considerations. The limitation of the linear speed of the beater is determined by the factor of prevent-

*Corresponding author: bys_ka87@mail.ru 
ing damage to the grains as a result of a direct impact and rebound of grains to the threshing drum.

The removal of the extreme stems from the drum occurs satisfactorily if the angle of the blade with the flow is equal to or greater than 90 degrees [6].

The parameters and operation modes of the beater must satisfy the following requirements - this is the stability of the transition zone processes and ensuring the greatest separation effect both directly in this zone and at the subsequent separation stage. The transition zone may become inoperative if there are prerequisites for unloading the flow of bread mass, then the advancement of the layer on the straw walker may stop, and the thresher will clog. The transfer of a heap over the surface of the front cascade is also undesirable [7]. The completeness of separation is reduced not only in the transition zone at the front cascade, but also on its main surface. Research indicates that with proper reflection of grains with a beater, losses behind a straw walker can be reduced.

Experiments have been carried out to study the effect of the beater on the work indicators of the straw walker.

The installation reproduced the scheme of the combine and allowed to widely vary the relative position of the working bodies of the threshing-separating group. Feed conveyor speed is $1 \mathrm{~m} / \mathrm{s}$. The duration of the experiments is about 30 seconds. The sampling time out of the straw walker is $8 \ldots 10 \mathrm{sec}$.

The operating mode of the threshing drum and keyboard straw walker in all experiments remained unchanged. The degree of influence of the studied factors was judged by the magnitude of losses behind the straw walker and patterns of sifting of grain along its length.

The studied parameters characterizing the mutual arrangement of the working bodies of the intermediate zone and accepted as factors determining the separation process on the straw walker are: $X_{1}$ - the angle of inclination of the first cascade of the straw walker; $\mathrm{X}_{2}$ beater rotation speed; $X_{3}$ - the position of the end of the deck on the surface of the drum, which is determined by the distance along the vertical diameter of the drum from the bottom point. The position of the deck allows you to adjust the flow direction of the heap relative to the axis of the beater; $\mathrm{X}_{4}$ - the position of the beater relative to the surface of the drum. It is fixed by the angle of inclination to the horizon of the line connecting the centers of the beater and the drum. All other possible movements of the beater are excluded from the study, since removing it from the drum leads to poor mass removal from the scourge.

Table 1. The value of the factors.

\begin{tabular}{|c|c|c|c|c|}
\hline Levels & $\begin{array}{c}\mathbf{X}_{\mathbf{1}} \\
\mathbf{d e g}\end{array}$ & $\begin{array}{c}\mathbf{X}_{\mathbf{2}} \\
\mathbf{r p m}\end{array}$ & $\begin{array}{c}\mathbf{X}_{\mathbf{3}} \\
\mathbf{s m}\end{array}$ & $\begin{array}{c}\mathbf{X}_{\mathbf{4}} \\
\mathbf{d e g} .\end{array}$ \\
\hline Main level (0) & 20,5 & 800 & 18,5 & 36,0 \\
\hline Range of variation & 9,0 & 160 & 7,0 & 12,0 \\
\hline Upper Level (+1) & 29,5 & 960 & 25,5 & 48,0 \\
\hline Lower level (-1) & 11,0 & 640 & 11,5 & 24,0 \\
\hline
\end{tabular}

To obtain the quantitative information about the influence of each selected factor and their interactions, a complete factor $2^{4}$ experiment was planned. The experimental design matrix and experimental results are given in table 2 ( $\mathrm{y}$ - is the percentage of grain allocation in the first cascade, calculated by the total amount of grain received by the straw walker).

After statistical processing of the experimental results, the dependence of the percentage of grain spreadability in the first cascade on the accepted factors is obtained in the form of the following regression equation:

$$
\mathrm{Y}=39,8-2,4 x_{1}+0,79 x_{2}+1,6 x_{3}+1,23 x_{4}-1,16 x_{2} x_{4}+3,5 x_{3} x_{4}-2,7 x_{1} x_{3} x_{4} .
$$


This expression is written in relatively independent variables in encoded form. The transition from the actual values of the factor to the coded one is performed according to the formula:

$$
x_{i}=\left(\mathrm{X}_{\mathrm{i}}-\mathrm{X}_{0 \mathrm{i}}\right) / \Delta \mathrm{X}_{\mathrm{i}}
$$

where $x_{i}$ - factor code;

$\mathrm{X}_{\mathrm{i}}$ - actual value of the factor;

$\mathrm{X}_{0 \mathrm{i}}$ - basic level of variation;

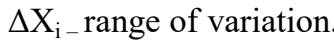

Based on the results of the experiments, the following conclusions can be made. Among isolated factors, the most significant influence on the separation process is exerted by the angle of inclination of the first cascade of straw walker - factor x1. The minus sign in front of it in the regression equation indicates the need to reduce this angle to obtain a high percentage of grain spillability.

The significance of the pair interaction $x_{2} x_{4}$ - the speed of rotation of the beater and its position relative to the surface of the straw walker indicates the existence of a relationship between them, and the minus sign in the equation indicates their mutual inconsistency. To increase the allocation of grain in the first cascade at a low position of the beater, a high speed of rotation is necessary, at the upper position it is small.

The second pair interaction $x_{3} x_{4}$ indicates the presence of a relationship between the position of the beater and the angle of departure of the product from the concave. A simultaneous increase in these factors increases the percentage of grain spillability in the first cascade and at higher values it reaches $50 \%$. The largest value of the coefficient in the equation in front of the $x_{3} x_{4}$ term shows the greatest significance of the influence of these factors on the separation process compared to the others.

Among the triple interactions, only one was significant $-x_{1} x_{3} x_{4}$. It connects the structural parameters of the arrangement of the working bodies of the intermediate zone and indicates that in order to obtain the effect of increased grain separation, it is necessary to reduce the angle of inclination of the first cascade, raise the beater axis above the straw walker and increase the departure angle of the threshed product, thereby ensuring a counter feed of the heap to the bitter. A simultaneous change in these parameters increases the space in the area between the drum and the straw walker, which positively affects the structure of the heap layer on the keys. The optimal location of the beater, deck, and straw mill, which ensures maximum grain separation in the first stage, is shown in table 2 in experiments 18,19 , and 20.

Table 2. The optimal location of the beater, deck, and straw mill, which ensures maximum grain separation in the first stage.

\begin{tabular}{|c|c|c|c|c|c|c|}
\hline \multirow[t]{2}{*}{ Exp.number } & \multicolumn{5}{|c|}{ Codes } & \multirow{2}{*}{$\begin{array}{c}\text { Experience } \\
\text { data. } \%\end{array}$} \\
\hline & $X_{0}$ & $X_{1}$ & $X_{2}$ & $X_{3}$ & $X_{4}$ & \\
\hline 1 & + & - & - & - & - & 45.2 \\
\hline 2 & + & - & - & - & + & 36.3 \\
\hline 3 & + & - & - & + & - & 34.5 \\
\hline 4 & + & - & - & + & + & 50.4 \\
\hline 5 & + & - & + & - & - & 46.2 \\
\hline 6 & + & - & + & - & + & 34.3 \\
\hline 7 & + & - & + & + & - & 38.7 \\
\hline 8 & + & - & + & + & + & 52.0 \\
\hline 9 & + & + & - & - & - & 52.6 \\
\hline 10 & + & + & - & - & + & 36.8 \\
\hline 11 & + & + & - & + & - & 34.2 \\
\hline 12 & + & + & - & + & + & 42.1 \\
\hline
\end{tabular}




\begin{tabular}{|l|c|c|c|c|c|c|}
\hline 13 & + & + & + & - & - & 38.1 \\
\hline 14 & + & + & + & - & + & 36.1 \\
\hline 15 & + & + & + & + & - & 39.1 \\
\hline 16 & + & + & + & + & + & 40.2 \\
\hline 17 & 0 & 0 & 0 & 0 & 0 & 42.0 \\
\hline 18 & & 15.5 & 830 & 21.5 & 39 & 46.3 \\
\hline 19 & & 10.5 & 860 & 24.5 & 42 & 53.7 \\
\hline 20 & & 5.5 & 890 & 27.0 & 45 & 58.6 \\
\hline
\end{tabular}

Studies indicate that if the grain is properly reflected by the beater, losses can be reduced behind the straw belt.

To analyze the ability of beaters of various shapes to reflect grains and a reasonable choice of a rational design, he developed a technique for constructing grain dispersion sectors [2]. Sectors give a picture of the reflection of those grains in a stream of heaps that are not affected by stems during their movement. This idealization of the process allows us to consider the case of the largest dispersion of grains. If the parameters of the beater, found on the basis of interaction with pure grains, provide reflection of it to the surface of the keys, then, probably, in the flow of rough rust that carries with it the largest amount of grain, the grains will not be thrown to the roof of the thresher with beater blades [8].

The construction of sectors is based on the laws of reflection of a single grain under the influence of a beater blade on a parallel flow of grains. The scheme of the oncoming impact of grain on the blade is considered.

Sectors are constructed in the following sequence [2]. Conditionally considering the forward movement of the beater relative to the grain flow, we select the zone of action of the beater blades 6-10-12-1-6 (Fig. 1). The instantaneous position of the blade zone is divided into separate "elementary" areas. Then the dispersion sector of each of them is built. The boundaries of each sector are determined by two extreme vectors of the reflection speed of particles located in a given area. Vectors are built directly on the drawing. The dispersion sector of the "elementary" site contains the amount of grain proportional to the ratio of the site to the area of the whole figure 5-10-12-1-6. From the totality of superimposed sectors, a common dispersion sector is constructed relative to the fixed center of the beater [9-13].

To verify the theoretical dispersion pattern, special experiments were carried out on the interaction of beater with real grains. The reflection pattern was determined by the distribution of grain adhering to the curved shield with solid oil. A comparison of the theoretical scattering sectors with the experimental ones showed a satisfactory coincidence of the position of the sectors relative to the beater and the nature of the distribution of grains in it (Fig. $1)$. 

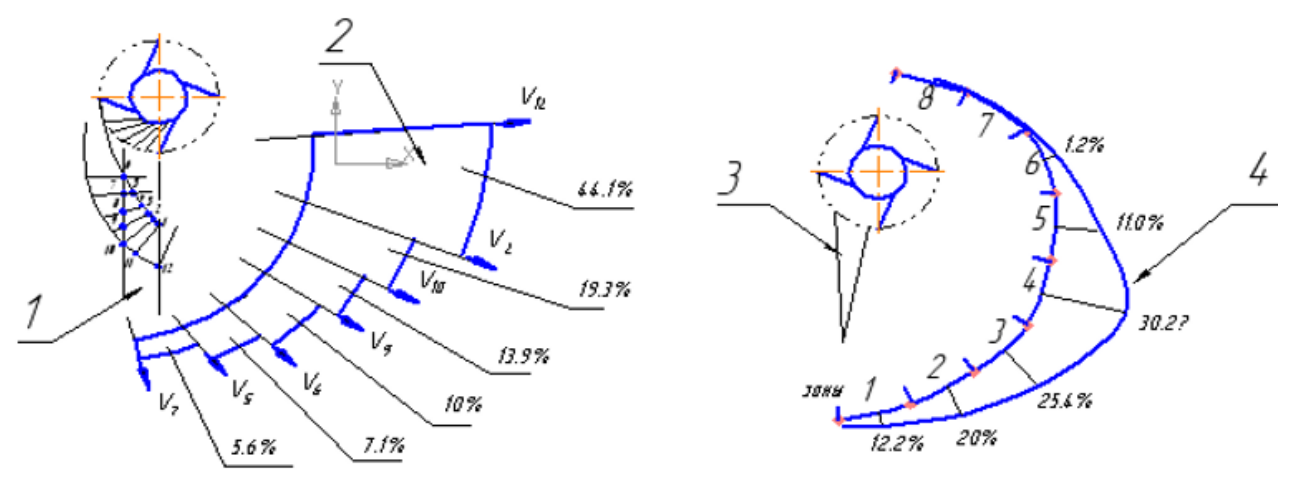

Fig. 1. Comparison of the theoretical sector of reflection of grains with the experimental: 1 - theoretical flow of grains; 2 - theoretical sector of reflection; 3 - direction of grain feed to the bitter in the experiment; 4 - experimental sector of reflection on the shield with solid oil.

A comparison of the dispersion sectors allows one to analytically study the effect on the pattern of reflection of grains of the beater structure, rotation speed and position relative to the flow.

The best results were obtained with a cylindrical beater with curved linear blades.

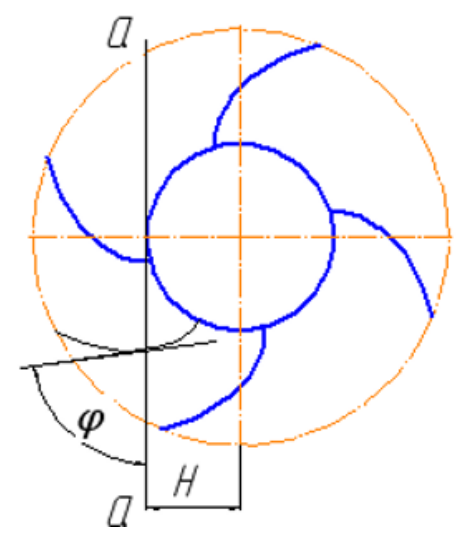

Fig. 2. Curved blade shape.

The shape of the curved line of the blade is plotted under the following condition. When the blades rotate in the zone of interaction with the theoretical flow in each of its instantaneous positions, the angle of encounter $\varphi$ with the incident flow equal to 90 degree should be provided (Fig. 2).

The constructions are made for the flow line facing the drum. In this case, the grains are most concentrated in the lower part of the dispersion sector and are directed to the beginning of the first cascade of straw walkers.

This design of the beater and its position contributes to the uniform distribution of grains in the dispersion sector, which increases the amount of grain that can break through to the surface of the keys even during the free flight of the rough heap from the beater to the straw walker, and also determines the uniform distribution of grains along the layer height by the first cascade [14-15].

The recommended position of the beater in the transition zone of the threshing group is shown in Fig. 3. 


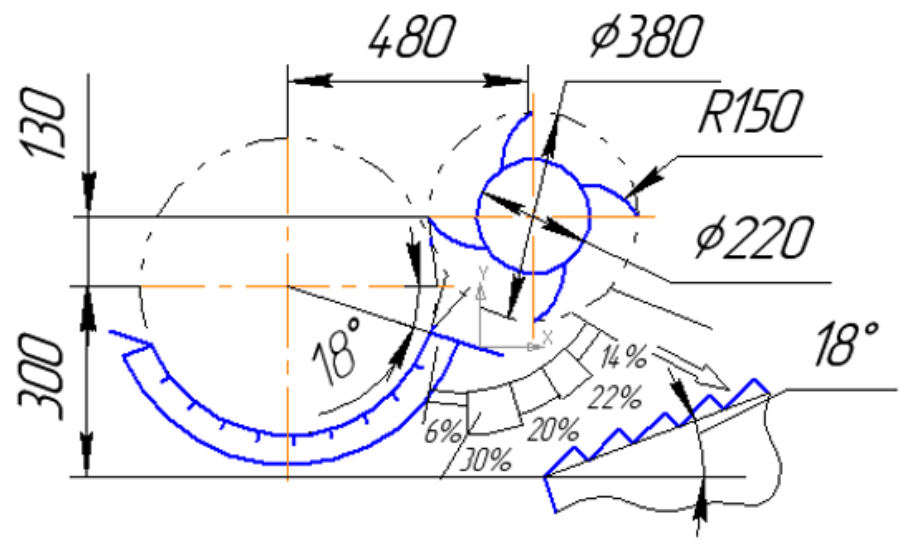

Fig. 3. A variant of the experimental scheme of the threshing group.

The effectiveness of this scheme, from the point of view of reducing grain losses behind a straw walker, compared with other possible options for transferring mass from a drum to a straw walker using a bumper beater, was confirmed by experiments.

The considered methodology for analyzing the operation of a breaker beater with the help of grain dispersion sectors in the reflected rough pile flow can be used to study processes in the transition zone.

\section{References}

1. V.I. Zubkov, Fundamentals of the mechanics of the medium of discrete particles: Scientific publication (DSTU Publishing Center, Rostov-on-Don, 2010)

2. E. Kozyrev, Century. Grain dispersion of grains with a bumper beater of a combine harvester. Design of the working bodies of agricultural machinery (RISCH, Rostovon-Don, 2010)

3. Y. Yu, H. Fu, J. Yu, Advanced Powder Technology 26(5), 1400-1409 (2015)

4. X. Lizhang, L. Yaoming, M. Zheng, Z. Zhan, W. Chenghong, Biosystems Engineering 114(2), 146-156 (2013)

5. R. Myhan, E. Jachimczyk, Biosystems Engineering 145, 93-107 (2016)

6. S.-H. Park, G. Park, Advances in Space Research 65(11), 392-406 (2020)

7. Y. Deng, L. Zhang, H. Hou, B. Yu, D. Sun, Powder Technology Volume 353(15), 473 488 (2019)

8. T. Magney, J. Eitel, D. Huggins, L. Vierling, Agricultural and Forest Meteorology 217, 46-60 (2016)

9. J. Ewel, L. Schreeg, T. Sinclair, Trends in Plant Science 24(2), 121-129 (2019)

10. R. Maqbool, M. Sajjad, I. Khaliq, A. Reham, A. Khan, S. Khan, Am-Euras. J. Agric. Environ. Sci. 8(2), 216-224 (2010)

11. M. Akhalkatsi, Genetic Diversity and Erosion in Plants (Springer International Publishing, Switzerland, 2015) ISBN 978-3-319-25637-5

12. T. Girgvliani, The History of Aboriginal Forms of Wheat Varieties of the Upper Svaneti (Artanuji, Tbilisi, 2010)

13. I. Badretdinov, S. Mudarisov, R. Lukmanov, V. Permyakov, R. Nasyrov, Computers and Electronics in Agriculture 165, 104966 (2019) 
14. D. Sun, D. Chen, S. Wang, X. Wang, IFAC-PapersOnLine 51(17), 363-367 (2018)

15. R. Karmulla Chaab, S. Hossein Karparvarfard, H. Rahmanian-Koushkaki, A. Mortezaei, M. Mohammadi, Journal of the Saudi Society of Agricultural Sciences 19(2), 179-184 (2020) 